181 LeFt VENTRICULAR EJECTiOH PATterins in CHILDREN WITH OUTFLOW OBSTRUCTION Dolores Vitullo; Ot to Thilenius; Rene A. Arcilla; University of Chicago, Chicago, Illinois The pressure/volume changes during earlv $\left(E_{3}\right)$, mid (M 3 ) and late ( $L_{3}$ ) thirds of ejection were analyzed in 20 normal children (II) 7 aortic coarctation (Co), and 20 aortic stenosis (AS). Mean peak systolic gradient was $30 \mathrm{mmHg}$ in $\mathrm{Co}$, and 31 in AS. Ejection fraction at $E_{3}, M_{3}$, and $L_{3}$ were $0.33,0.36$ and 0.27 for $\mathrm{N} ; 0.35$ 0.37 and 0.28 for Co; $0.24,0.41$ and 0.28 for AS Tsision-time index (TTI) in mmis-sec, stroke index (SI), output index (OI), ejection rate (SI/sec) and $\mathrm{sI} / \mathrm{Tr}$ ratio in $\mathrm{cc} / \mathrm{mmHg}-\mathrm{sec} / \mathrm{m}^{2}$ were obtained. These are summarized below ( $P$ values vs $\mathrm{H}: *-<.05$ $\left.* *_{-}<.001\right)$.

\begin{tabular}{|c|c|c|c|c|c|c|c|c|c|}
\hline \multirow[b]{2}{*}{ Gr } & \multirow{2}{*}{$\frac{\mathrm{OI}}{\mathrm{E}_{3}}$} & \multicolumn{2}{|c|}{$\left(1 \mathrm{it} / \mathrm{m} / \mathrm{m}^{2}\right)$} & \multirow{2}{*}{$\frac{\mathrm{sI} / \mathrm{sec}}{\mathrm{E}_{3}}$} & \multicolumn{2}{|c|}{$(\mathrm{cc} / \mathrm{sec})$} & \multirow{2}{*}{$\frac{\mathrm{SI} / \mathrm{TTI}}{\mathrm{E}_{3}}$} & \multicolumn{2}{|c|}{ Ratio } \\
\hline & & $M_{3}$ & $\mathrm{~L}_{3}$ & & $\mathrm{M}_{3}$ & $\mathrm{~L}_{3}$ & & $\mathrm{M}_{3}$ & $\overline{L_{3}}$ \\
\hline $\mathrm{N}$ & 2.18 & 1.61 & 0.78 & 226 & 166 & 81 & 3.91 & 1.67 & 0.81 \\
\hline $\mathrm{Co}$ & 2.29 & 1.55 & 0.75 & 242 & 163 & 82 & 3.18 & 1.54 & 0.64 \\
\hline$\overline{\mathrm{AS}}$ & 1.55 & 1.99 & 0.88 & $\begin{array}{l}162 \\
\star \star *\end{array}$ & 203 & 90 & 2.51 & 1.78 & 0.84 \\
\hline
\end{tabular}

Normal ejection is characterized by maximal flow and high outnut/force ratio during $E_{3}$. This pattern is absent in $A S$ but is preserved in Co due to unobstructed flow to aorta and presence of collaterals.

182 EFFECT OF EXPERIMENTAL CYANOSIS ON PLATFLITT SURVIVAL J. Deane Waldman, Carol R. Norwood, William I.

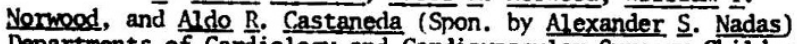
Departments of Cardiology and Cardiovascular Surgery, Children's lospital Medical Center, Roston

In effect of cyanosis on platelet survival, experimental cyanosis was produced in dogs by anastomosing the left atrial apnendage to the main pulmonary artery. The six cyanotic animals used in this study had arterial $0_{2}$ saturations of $71:-858$ and elevated hematocrits. Bv one month following surgery, the 51 chromium-1abeled autologous platelet half-1ife (PII) decreased 15\%-60\% from preoperative values: cyanotic dogs had progressive reduction of months. No reduction in PII occured in three sham operated conmonths. No animals.

Survival of platelets exchanged between cyanotic and control animals was determined. Platelets from cvanotic dogs studied in control animals had a $69 \%-87 \%$ shorter survival than the autologous PYL of the control animals, indicating an abnormality intrinsic to the platelet produced in the cyantic dog. Normal platelets from control animals transfused into cyanotic dogs had the identical reduced survival of autologous platelets in that cyanotic animal, suggesting that some determinant of transfused platelet survival is extrinsic to the platelet.

Three months after shunt closure in two dogs, the reduced P.II has persisted.

183 MEDICAL MANAGEMENT OF SEVERE SYSTEMIC HYPERTENSION IN INFANTS WITH COARCTATION OF THE THORACIC AORTA. Gary L. Way, Robert R. Wolfe, Robert L. McGrath and James J. Nora. Depts. of Pediatrics, Univ. of

$16 / 56$ infants (ages 2 wks to 6 mos) with isolated coarctation of the thoracic aorta presented with congestive heart failure and severe systemic hypertension ranging from $210 / 140$ to $150 / 80$ mmHg. Because of the surgical risks in symptomatic infants and the probability of recoarctation, conventional anticongestive medical management was instituted. The response to the antimed chanced by diminishing aftercongestive measures wal propranolol $(.05-1.0 \mathrm{mg} / \mathrm{kg} /$ day) with maximal antihypertensive effects noted by 1-4 wks. Rebound hymaximal antihypertensive effects noted by 1-4 wks. Rebound hypertension was noted in 4 patients with propranolol withdrawal. tension. No complications related to beta blockade have been seen in the infants treated. From this data we conclude that the antihypertensive effects from propranolol far outweigh the ne negative inotropic effect in infants with coarctation of the aorta may allow deferral of surgery to a more optimal size and clinical status.
184 PACEMAKERS IN YOUNG PATIENTS: 1976 . V1ctor whitman, William Berman, Jr., G. Frank 0. Tyers, (Spon. by cal Center, Depts. of Pediatrics and Cardiothoracic Surgery. We have reviewed our recent experience with 10 young pat lents requiring chronic cardiac pacing. Detalls of the performance of the most recent two generators are summarized. Six patients required pacing for symptomatis congenital complete heart block. two for postoperative complete heart block. one for heart block associated with idiopathic myocardiopathy and one for the sick sinus syndrome. Pacemaker generators were implanted beneath the pectoral muscle to elminate cutaneous erosion in small or slender pat1ents. Seven patients underwent transvenous pacemaker electrode implantation into the right ventricle. Although our patients have had a variety of generators, we currently use the BrownleeTyers, rechargeable silver modifled mercury-zinc generator, with a proven $11 \mathrm{fe}$ span of 6 years and an anticipated 11fe span of 20 years. All patients have been montored transtelephonically. In those requiring change, all on an elective basis, the average conventional generator life span has been 27 months (range 20-44 months). None of the Brownlee-Tyers generator units have required replacement. No wire fractures have occurred, though one transvenous electrode required repositioning 1 month following inser$t$ ton. No long term electrode complications have occurred in children with transvenous placement including one patient in whom the electrode was p'aced at 7 years of age and followed for 9 years. The improved prognosis detalled in this report is the result of anproved generator and electrode construction, surgical technique,

185 EARLY LIGATION OF PDA, EFFECT ON BPD AND POSTOPERATIV VENTILATOR TIME. Leighton $S$. Whitsitt, Melvin Baden, R1chard C. Traugott, and Robert L. Treasure, Newborn Svc, Brooke Army Med. Ctr., San Anton10, TX. (Spon. by R. Steele) A retrospective and prospective study was undertaken to determine whether early ligation of PDA (7 days of age or less) resulted In a decreased Incidence of BPD and shorter period of vent1latory support in infants with RDS and cardiopulmonary fallure. The diagnosis of a PDA was made on clinical grounds (murmur, hyperactive precordium and pulses) with several infants having aortographic and/or echocardlograph1c confirmation of a PDA prior to surgery. The early group consisted of 16 infante (B.W. 1240 gms, G.A. 29.2 weeks), operated on at a mean of 4.8 days, while the late group consisted of 20 infants (B.W. $1175 \mathrm{gms}$, G.A. 28.5 weeks) operated on at 14.4 days.

Infants developing clinical and $X$-ray evidence of BPD (15 of 36,417 ) recelved assisted ventilation for 8.2 days preoperatively and 16.6 days postoperatively. Infants not developing BPD received assisted ventilation for 5.9 days preoperatively and 3.0 days postoperatively. Infants operated on early $\leqslant 7$ days) received 4.7 days of vent1latory support postoperatively of whom only $25 \%(4 / 16)$ developed BPD. Infants operated beyond 7 daye required 16.6 days of ventilatory assistance postoperatively. Among th1s group $55 \%$ developed BPD $(11 / 20)$. The combined mortality was $36 \%(13 / 36)$ with $35 \%(7 / 20)$ in the late group and $37 \%(6 / 16)$ in the early group. There was 1 perioperative death and 12 late deaths. These data indicate that while there was no statistical
difference in mortality, there was a significant decrease in total duration of ventilatory time and BPD in the early treated group.

186 THE INFLUENCE OF INDOMETHACIN ON NEONATAL RENAL

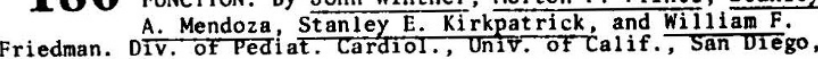

\section{School of Medicine.}

Transient renal dysfunction has been observed in premature infants receiving indomethacin (indo) to inhibit prostaglandin (PG) synthesis and hence constrict their patent ductus arteriosus. The present study was designed to e"aluate in 14 newborn lambs the influence of high $(7.5 \mathrm{mg} / \mathrm{kg})$ and $10 \mathrm{w}(0.2 \mathrm{mg} / \mathrm{kg})$ doses of indo. on renal blood flow (RBF), glomerular filtration rate (GFR), and urine flow $(\dot{V})$. The latter indices of renal function were studied by $131 \mathrm{I}$-hippuran and $14 \mathrm{C}$-inulin clearances in conscious, chronicby 1 ill reduced RBF significantly at 4 hours (high $12.4 \pm 1.2$ (SE), lowreduced RBF significantly at 4 hours (high $12.4 \pm 1.2$ (SE), low-
$12.8+1.0 \mathrm{ml} / \mathrm{kg} / \mathrm{min}$ ) but on $1 \mathrm{y}$ high-dose animals were significant $1 \bar{y}$ lower than the control group at $12(8.2 \pm 0.8, \mathrm{p}<0.025)$ and 24 hours $(6.5+0.9, \mathrm{p}<0.001)$. PGE levels, determined by radioimmunoassay, correlated directly with alterations in RBF.GFR was unaltered in all groups. Urine flow was significantly lower than in the control group at $24 \mathrm{hrs}$, only in the high-dose indo. group $(0.08+0.2$ vs $0.15+0.1 \mathrm{cc} / \mathrm{kg} / \mathrm{min}, \mathrm{p}<0.025)$. Filtration group $(0.08 \pm 0.2$ vs $0.15 \pm 0.1+\mathrm{cc} / \mathrm{kg} / \mathrm{min}, \mathrm{p}<\mathrm{h}$. these data suggest that the renal dysfunction observed trans-

iently in some human prematures may be dose-related and support the need to carefully monitor renal function in continued clinical applications of a pharmacological approach to constriction of the ductus arteriosus. 